\title{
Laser instant implant impression method: A case presentation
}

\section{Metoda wycisku w implantacji natychmiastowej z użyciem lasera (LIIIM) - prezentacja przypadku}

\author{
Jacek Matys ${ }^{1-3, A-D}$, Katarzyna Świder ${ }^{3, D}$, Rafał Flieger ${ }^{4, D, E}$ \\ 1 Department of Dental Surgery, Wroclaw Medical University, Wrocław, Poland \\ 2 Student of the Master in Laser Dentistry of Sapienza University of Rome, Italy \\ 3 Private Practice, Wschowa, Poland \\ ${ }^{4}$ Private Dental Healthcare, Kościan, Poland \\ A - research concept and design; $B$ - collection and/or assembly of data; $C$ - data analysis and interpretation; \\ $\mathrm{D}$ - writing the article; $\mathrm{E}$ - critical revision of the article; $\mathrm{F}$ - final approval of article
}

Address for correspondence

Jacek Matys

E-mail: jacek.matys@wp.pl

\section{Funding sources}

none declared

\section{Conflict of interest}

none declared

Received on September 1, 2016

Revised on 0ctober 24, 2016

Accepted on 0ctober 26, 2016

\begin{abstract}
Dental impressions are mainly used to record the geometry of hard and soft tissue and the relations between teeth and the adjacent tissues. In implantology, precise implant impressions are necessary to obtain the best possible detailed reproduction of the implant site and the passive intraoral fit of the implant framework. However, ensuring those necessities in the interdisciplinary treatment of orthodontic patients requires revised impression techniques and materials. In this study a modified one-stage putty-wash pick-up implant impression procedure was used, incorporating the use of two additional silicone materials and modeling wax. Additionally, an Er:YAG laser was used to obtain a better emergence profile for implant restorations and an immediate impression, which shortened the prosthodontic stage in patients undergoing orthodontic treatment. The technique described here for taking the impression and creating the emergence profile offers dental practitioners additional options in implantoprosthodontic treatment of orthodontic patients, as the method is characterized by simple preparation and satisfactory implant site reproduction.
\end{abstract}

Key words: dental implants, orthodontic treatment, Er:YAG laser, prosthetic impression, laser surgery

Słowa kluczowe: implanty stomatologiczne, leczenie ortodontyczne, laser Er:YAG, wycisk protetyczny, chirurgia laserowa
DOI

10.17219/dmp/66363

Copyright

(C) 2017 by Wroclaw Medical University

and Polish Dental Society

This is an article distributed under the terms of the

Creative Commons Attribution Non-Commercial License

(http://creativecommons.org/licenses/by-nc-nd/4.0/) 
The use of endosseous titanium implants has been successfully implemented in the treatment of patients with edentulism of various extents. ${ }^{1-3}$ Nowadays, implants are extensively used in several disciplines of dentistry. Patients affected with malocclusion and partial edentulism frequently insist on being treated as quickly as possible. Therefore, an interdisciplinary approach and precise planning are needed to obtain satisfactory results. Orthodontic treatment can contribute to the successful use of implants through vertical development of the peri-implant site (using tooth extrusion) and the creation of space for implant restorations. ${ }^{1}$ In addition, osseointegrated dental implants have been used for a variety of purposes in orthodontics. The placement of dental implants can provide a good quality of anchorage control, as well as a method to reposition the natural teeth. ${ }^{1-3}$

However, interdisciplinary treatment can entail some difficulties. If the implant placement takes place during orthodontic treatment and before its finalization, a satisfactory impression is hard to obtain. Elements of orthodontic appliances (wires, brackets, bands) can trap and damage the impression material. Usually the wires can be pulled out without problems prior to taking the impression, but removing brackets would be time-consuming and could disturb the treatment process. To overcome this problem, clinicians have come up with different methods to facilitate impressions of orthodontically banded teeth. The most widely used method is to cover the orthodontic brackets. Consequently, when the impression tray is removed the material tearing is minimized, or even eliminated in some cases. Maeda et al. proposed the use of a tube as block-out material for orthodontic brackets and arch wire while taking the impression for the production of a mouthguard. ${ }^{4}$ Rilo et al. suggested using small portions of utility wax; Croll and Castaldi proposed strips of utility wax; while Lorton recommended the use of strips of occlusal indicator wax compressed over bonded brackets prior to alginate impression. ${ }^{5-7}$ Sukotjo and Bocage proposed the use of an implant surgical template. ${ }^{8}$ However, all of these procedures involved the use of irreversible hydrocoloid as impression material, which cannot yield satisfactory impression results for implant procedures.

Another challenge the clinician can encounter during implant-supported restoration treatment of an orthodontic patient is the emergence profile. Multiple methods have been described that utilize direct, indirect or combined techniques. ${ }^{9}$ Tarlow, as well as Macintosh and Sutherland, formed the emergence profile on the master cast by trimming or burring the overabundance of the soft tissue substitute before the final crown framework was made. ${ }^{10,11}$ Reike suggested surgically repositioning a split flap and overcontouring the soft tissue around the healing abutment. ${ }^{12}$ Other methods incorporate the use of interim restorations made of an autopolymerizing resin or direct composite. ${ }^{13-17}$ Ntounis and Petropoulou proposed the use of a screw-retained provisional restoration that was adjusted regularly. ${ }^{15}$ Azer combined the method of using a rotary instrument to reshape the stone cast with the use of a provisional autopolymerizing resin crown that was gradually built up each week by adding more resin to the external gingival contours. ${ }^{17}$

One technique that offers the possibility of executing the impression immediately after implant exposure is the use of the Er:YAG laser, widely employed in surgical procedures. Identifying the patients' periodontal biotype is fundamental to the optimal planning of therapeutic management, especially in implantology. ${ }^{18}$ Matys et al. proposed the use of erbium lasers only in cases with sufficient keratinized tissue thickness. ${ }^{19}$ Hence, when the attached gingiva around the implants are insufficiently thick, the implants should be covered with subepithelial connective tissue grafts (SCTG) or free gingival grafts (FGG). ${ }^{20}$

To the best of the present authors' knowledge, the laser instant implant impression method (LIIIM) developed by the authors has not previously been described in literature. The method incorporates the use of two silicone impression materials and a modeling wax strip as block-out material for orthodontic brackets. An optimal emergence profile is obtained with the direct use of an Er:YAG laser.

\section{Case presentation}

A 20-year-old female patient was referred to one author's private practice (in Wschowa, Poland) from a general dentist, with the aim of restoring her missing teeth 12 and 22 (FDI notation system used), in which the germs had been missing from birth due to hereditary agenesis. It was decided that implantation would be the best course of action; however, as the patient wished to align her teeth in the process, she was referred to an orthodontist for assessment. Complete fixed orthodontic treatment was planned for the correction of crowding and a lack of space for future implants 12 and 22. The tooth alignment process meant that implant treatment would have to be staged. Six months before the planned termination of the orthodontic treatment, two implants (Superline, Dentium, Suwon, Korea), $4.0 \mathrm{~mm}$ in diameter and 10 $\mathrm{mm}$ in length, were inserted under local infiltrative anesthesia with articaine hydrochloride 4\% plus epinephrine 1:100000 (Orablock ${ }^{\circledR}$, Pierrel Group, Capua, Italy) and cover screws were fitted immediately.

After half a year, during which the adjacent bone healed, the patient came back to continue her implantoprosthodontic treatment. However, it is difficult to obtain accurate impressions before the completion of orthodontic treatment, since (as noted earlier) the brackets of orthodontic devices trap and tear the impression material. To bypass these problems, a modified one-stage putty-wash pick-up impression technique was used, with open tray (direct) procedure and an application of modeling wax for undercut coverage. 


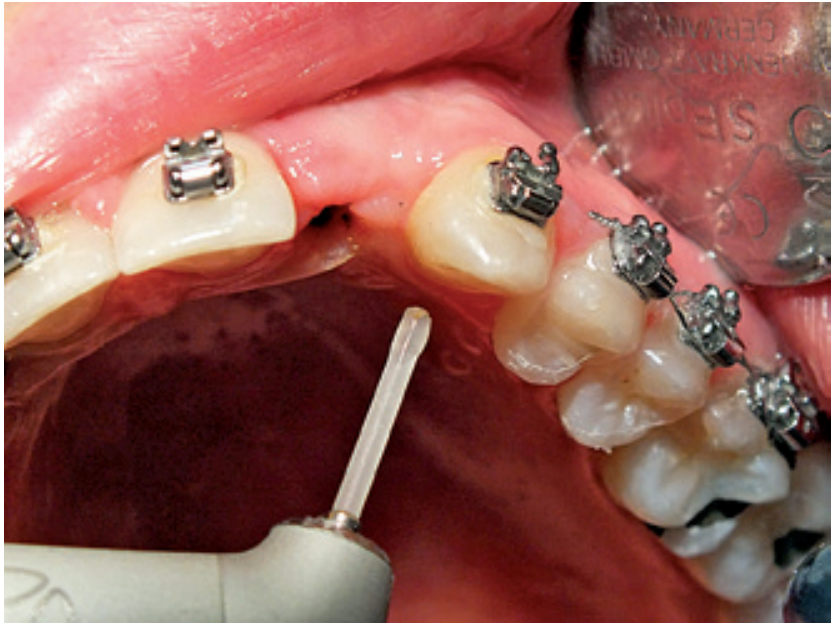

Fig. 1. Implants exposure and emergence profile was aquired using the Er:YAG LiteTouch ${ }^{\text {TM }}$ laser

Prior to taking the impression, the orthodontic upper arch-wire was removed. To shorten the time of final crown cementation, the implants were exposed using an Er:YAG LiteTouch $^{\mathrm{Tm}}$ laser (Syneron ${ }^{\mathrm{Tm}}$ Dental Lasers, Syneron Medical Ltd., Yokneam, Israel) (Fig. 1) with the following settings: pulse energy $300 \mathrm{~mJ}$, pulse frequency $18 \mathrm{~Hz}$, energy density per pulse $38.2 \mathrm{~J} / \mathrm{cm}^{2}$, mode for soft tissue (ST), cooling spray $5 \mathrm{~mL} / \mathrm{min}$, angle of the working tip $70^{\circ}$, size of the tip $1.0 \times 17 \mathrm{~mm}$, distance from the soft tissue $2 \mathrm{~mm}$. The use of the laser allowed fast homeostasis of the wound. An immediate impression for the final prosthodontic restoration was possible thanks to the lack of postoperative bleeding. Additionally, the use of the Er:YAG laser resulted in an emergence profile without any visible thermal damage (Fig. 2).

After this, direct transfer abutments were screwed onto the implants (Fig. 3). To facilitate access to the implant transfer, the open tray method was used; a custom impression tray was perforated (before the impression was taken, the hole was adjusted to line up with the position

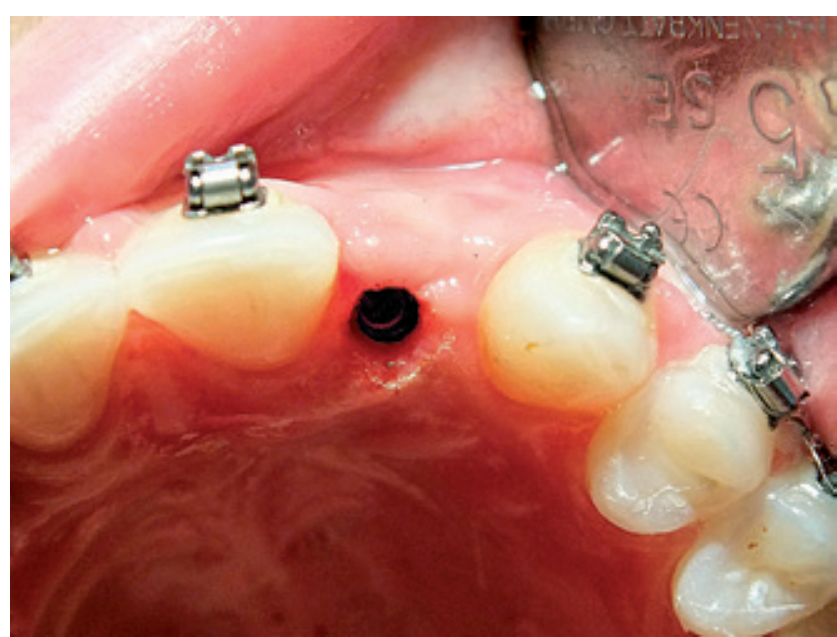

Fig. 2. Intraoral view of the emergence profile of the implant in position 22

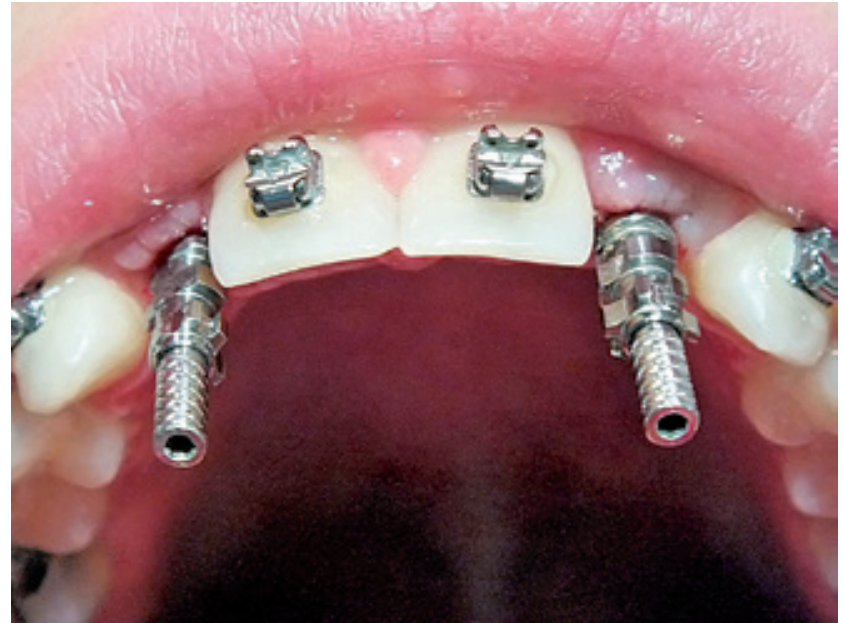

Fig. 3. Placement of the implant transfers

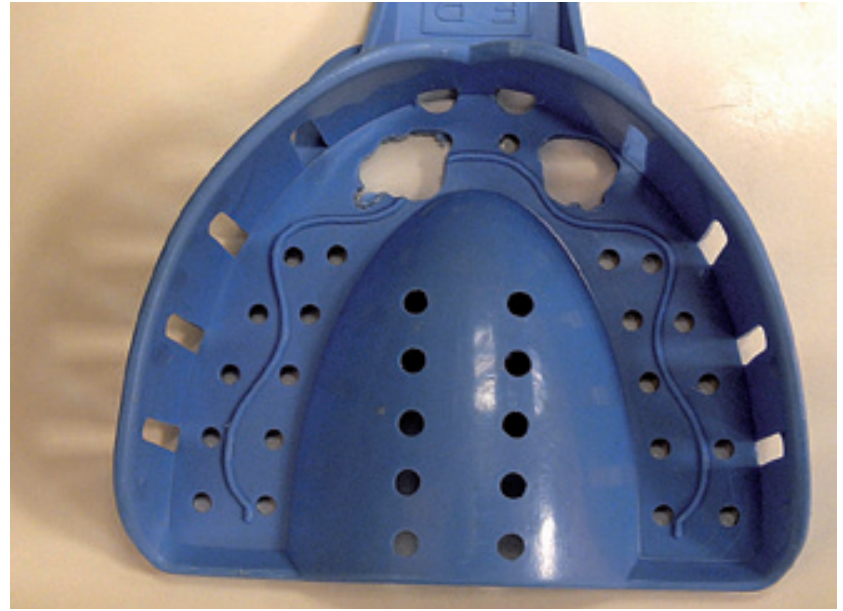

Fig. 4. View of the custom tray adjustments - inner side

of the transfer) (Fig. 4). The undercuts around the brackets were blocked with a strip of Vertex ${ }^{\mathrm{TM}}$ Modelling wax (Vertex-Dental, Soesterberg, The Netherlands); the material was heated to obtain the necessary shape and then folded three times (Fig. 5). It is very important to leave the space near the implants and adjacent teeth free to allow the impression material to enter. Light-bodied addition silicone material (Variotime ${ }^{\circledR}$ Medium Flow, Heraeus Kulzer, Hanau, Germany) was placed around the implant with an injection tip. At the same time, putty-bodied addition silicone material (Variotime ${ }^{\circledR}$ Dynamix Monophase, Heraeus Kulzer, Hanau, Germany) was loaded onto the tray by a dental assistant, using the Variotime Dynamix ${ }^{\circledR}$ Speed System (Heraeus Kulzer, Hanau, Germany). This allowed a full-arch impression with the transfer screws protruding through the tray (Fig. 6). Subsequently, with the tray still in place, the retaining screws were removed. In consequence, when the tray was taken out of the patient's mouth (using a swaying motion), the transfers 


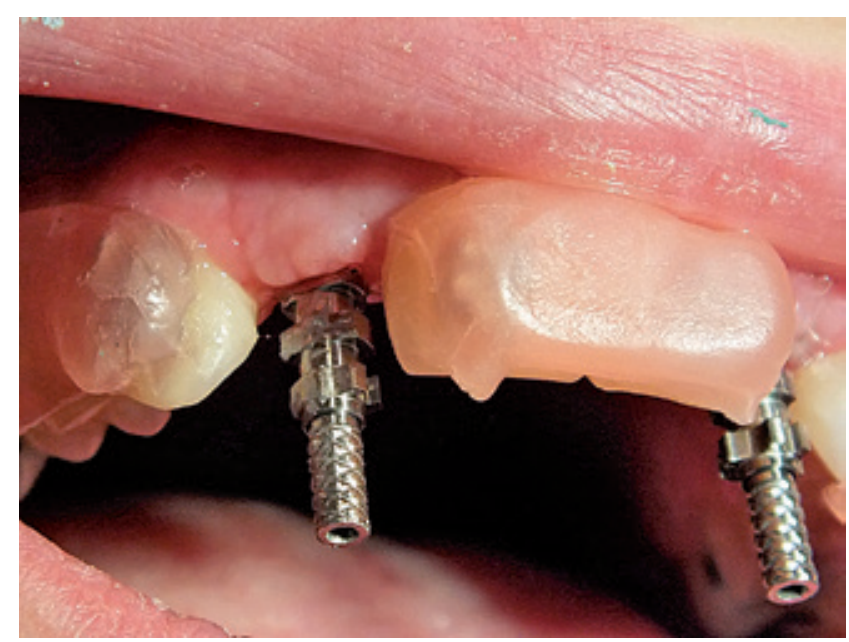

Fig. 5. The under cuts around the orthodontic brackets are blocket using the modeling wax strips - patient's right side view

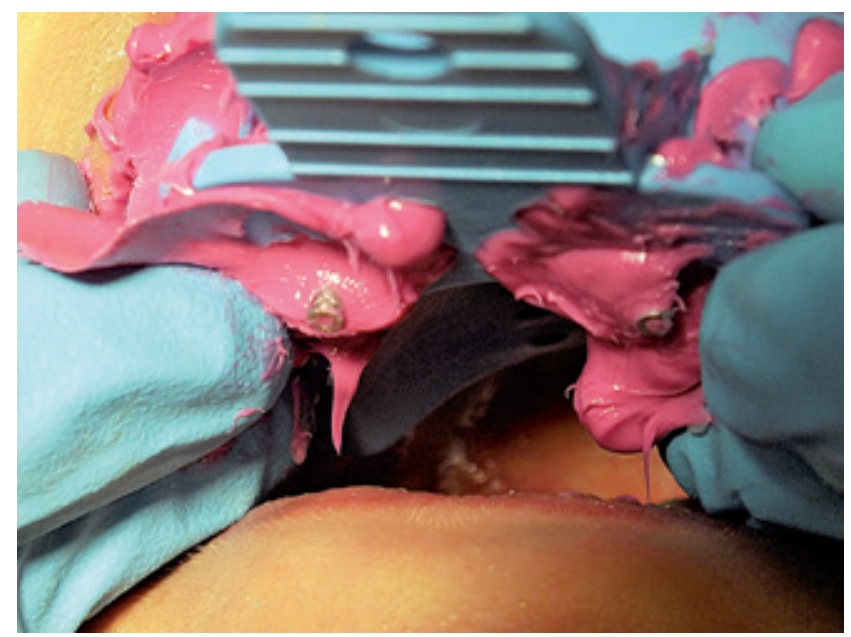

Fig. 6. View of the impression with the transfer screws protruded through the tray

were captured in the impression material. The presence of the wax prevented the impression material from tearing, and its thickness and ductility allowed easier tray removal. The implant analogs were then connected to the transfers in the impression material (Fig. 7-9). After the impressions were taken, temporary healing screws were placed onto the implants (Fig. 10). Healing screws with a diameter matching the implant emergence profile made with the laser were used, and after 7 hours the final screwretained crowns were made by a dental laboratory and cemented onto the implants (Fig. 11).

\section{Discussion}

Implant impressions during fully-banded orthodontic treatment can cause many difficulties for dental practitioners, as elements of the orthodontic appliances (brack-

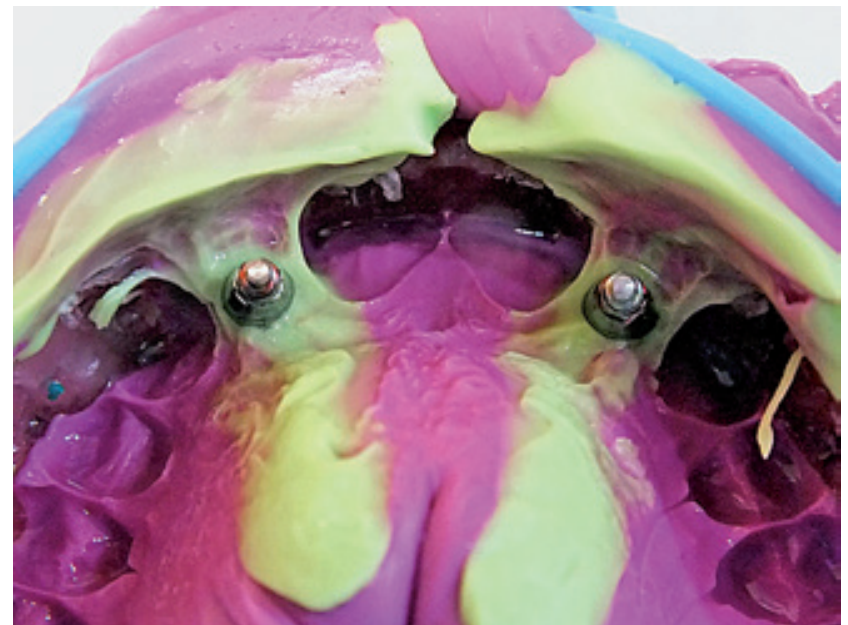

Fig. 7. Close-up of the implant analogs in impression material

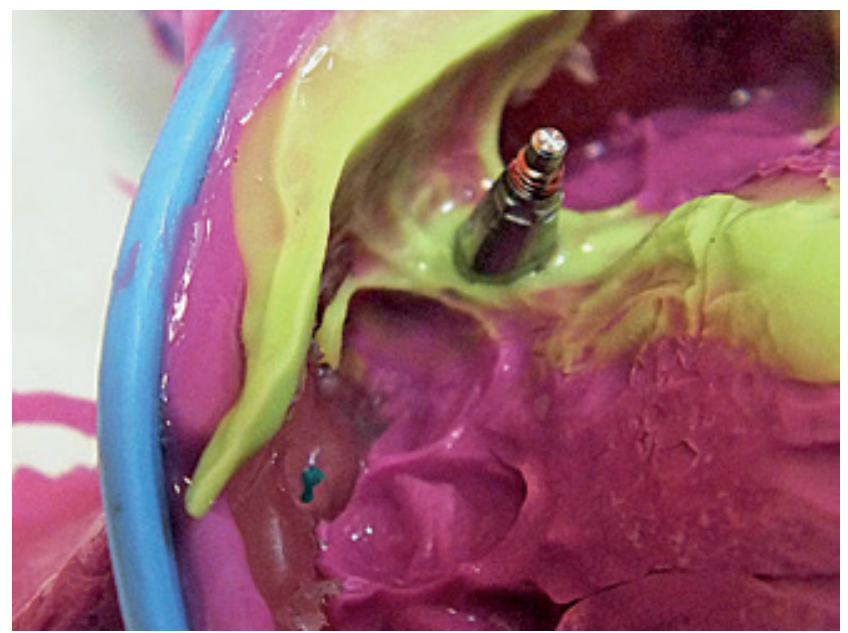

Fig. 8. Implant analog in position 22

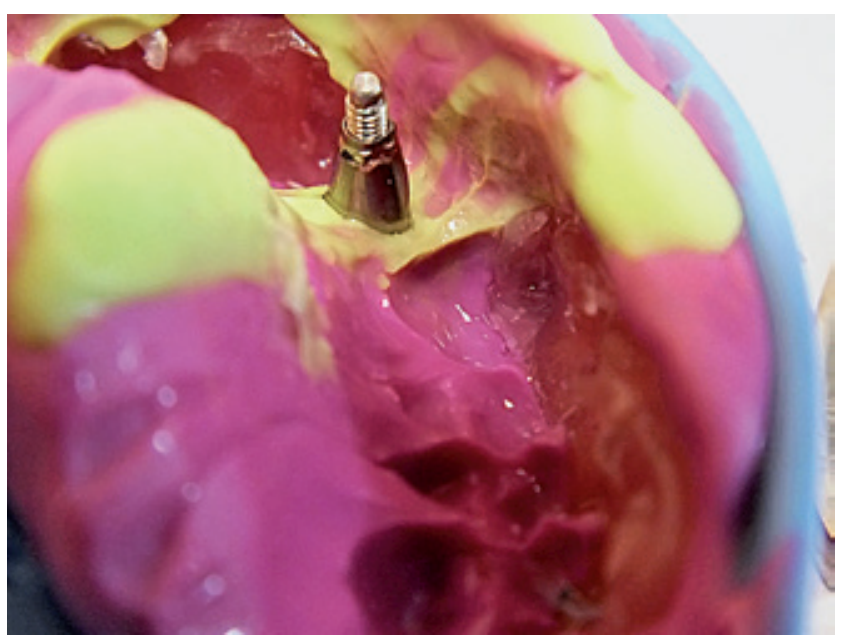

Fig. 9. Implant analog in position 12 


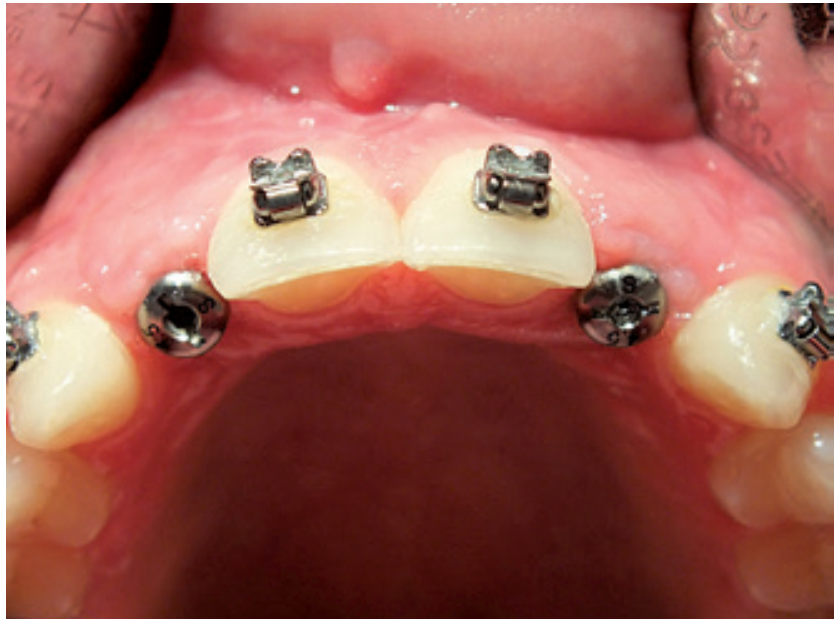

Fig. 10. Intraoral view of interim healing screws

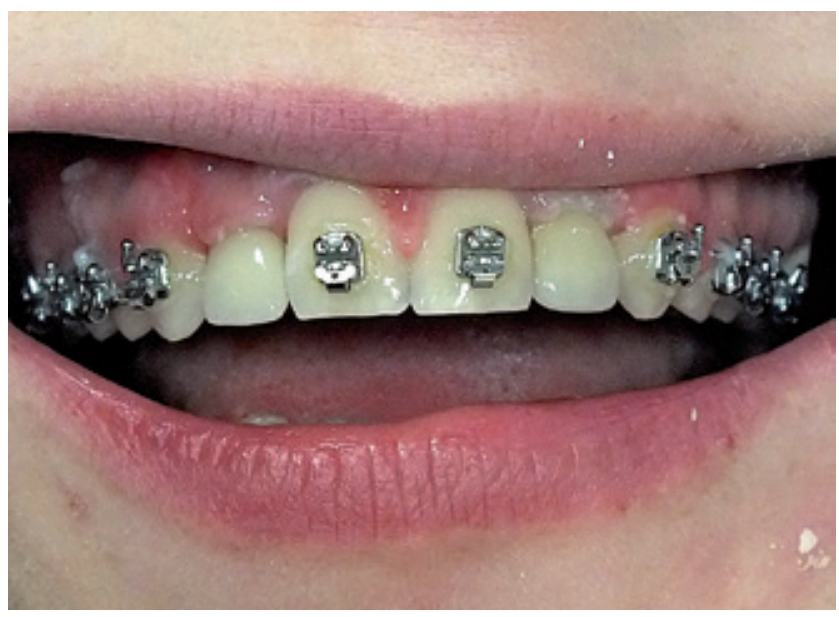

Fig. 11. View of the final screw retained crowns in position 12 and $22-$ without the orthodontic wire

ets, wires) can trap and tear the impression material. The easiest proven method to overcome these difficulties is to block the undercuts around the brackets with additional material. Maeda et al. proposed a use of a tube, while Sukotjo and Bocage recommend the use of an implant surgical template. ${ }^{4,8}$ However, those solutions are time consuming. The use of dental wax is a quick and inexpensive method that can accommodate orthodontically banded patients. The plasticity of the wax depends on the temperature. Due to its ductile nature when warmed, it allows easy shaping and molding. When cooled, however, it stays in the impression material and does not change its shape without extra applied force. The material has the added advantage of attaching well to brackets, in addition to peeling off easily. Consequently, it results in minimized material damage when the impression tray is removed. The first author to use this material was Lorton, who advised the use of strips of occlusal indicator wax. ${ }^{7}$ Rilo et al., along with Croll and Castaldi, proposed a cheaper material: utility wax. ${ }^{5,6}$ Rilo et al. suggested using small portions of the material, whereas Croll and Castaldi suggested using strips. ${ }^{5,6}$ Forming small portions of wax takes a little more time than the use of strips. The method proposed by the current authors incorporates the best of both of these techniques: folded strips of modeling wax are a faster and cheaper solution. Additionally, the thickness of the folded strip of wax allows simple tray removal even when using rigid A-silicone material.

The properties of the impression material (rigidity, accuracy) can influence the accuracy of the implant impression, cast and framework. ${ }^{21}$ The most frequently applied material for implant impressions is polyether; however, studies have shown that the use of A-silicon, as in the current study, yields comparable accuracy. ${ }^{21}$ The use of two A-silicone materials allows improved dimensional accuracy and less deformation ${ }^{22}$, compared to alginate material that most clinicians use for orthodontic patients. ${ }^{2-8}$ It also permits better detail reproduction and adhesion between the impression materials, compared to irreversible hydrocolloid material or an alginate and silicone combination. $^{22}$

Studies assessing the prosthetic impression quality of an implant emergence profile using the Er:YAG are scarce in the scientific literature. Matys et al. used a 3-point prosthetic impression scale (PIS) to visually assess the accuracy of the prepared soft tissue using an erbium laser. ${ }^{19}$ They found an ideal projection of the soft tissue (no bubbles or scratches: PIS1) in 4 cases; a satisfactory projection of the soft tissue (small bubbles, scratches: PIS2) in 19 cases; and an inaccurate projection of the soft tissue (cavities, large cracks in the impression material: PIS3) in 7 cases. They concluded that in $70 \%$ of the cases $(21 / 30)$ the quality of the implant emergence profiles prepared using an Er:YAG laser allowed a prosthetic impression to be taken immediately, without utilizing healing screws, which reduced the overall treatment time. ${ }^{19}$

The indirect techniques proposed by Tarlow or Macintosh and Sutherland require cast and/or soft tissue substitute modification, which prolongs the treatment and often requires excellent communication with the dental technician. ${ }^{10,11}$ The result depends mainly on skills of the technician. Direct techniques are easier to carry out. However, the surgical intervention in soft tissue proposed by Reike entails extended impression waiting time due to the need for local anesthesia and the postoperative bleeding. ${ }^{12}$ Solutions that incorporate the use of interim restorations very often do not ensure the ideal shape of the emergence profile (prefabricated abutments) or are dependent on the technician's skills (custom abutments). ${ }^{13-17}$ Nevertheless, the addition of an Er:YAG laser introduces a fast and easy method for obtaining an optimal emergence profile. The use of a laser excludes postoperative bleeding (optimal hemostasis), the need for suturing and local anesthesia. ${ }^{23}$ Laser intervention significantly reduces postoperative pain, discomfort and swelling, and causes only a minimal thermal rise in the bone around the implant. ${ }^{24-26}$ The ab- 
sence of bleeding permits immediate implementation of impressions for restorations, while other methods require healing time for the soft tissue. ${ }^{19}$

\section{Conclusions}

Regarding the new method presented here, the authors suggest that further comparison studies of the influence on implant collar height and crestal bone loss using LIIIM and traditional mucoperiosteal flap development are necessary. Furthermore, a long term randomized clinical trial should be performed to assess the emergence profile quality obtained using an Er:YAG laser.

Within the limitations of this single case study, the outcomes could indicate that the technique described here for taking the impression and creating the emergence profile offers dental practitioners additional options in the implantoprosthodontic treatment of orthodontic patients, as the method is characterized by simple preparation and satisfactory implant site reproduction.

\section{References}

1. Rose TP, Jivraj $S$, Chee $W$. The role of orthodontics in implant dentistry. Br Dent J. 2006;201:753-764.

2. Farret MM, Farret MM, Carlesso J, Carlesso O. Orthodontic treatment and implant-prosthetic rehabilitation of a partially edentulous patient. J Prosthodont. 2013;22:587-590.

3. Drago CJ. Use of osseointegrated implants in adult orthodontic treatment, a clinical report. J Prosthet Dent. 1999;82:504-509.

4. Maeda Y, Matsuda S, Tsugawa T, Maeda S. A modified method of mouthguard fabrication for orthodontic patients. Dent Traumatol. 2008;24:475-478.

5. Rilo B, Lago L, Da Silva L, Fernández-Formoso N. Implant impression for full-banded orthodontic patient. J Oral Implantol. 2016;42:292-293.

6. Croll TP, Castaldi CR. Custom sports mouthguard modified for orthodontic patients and children in the transitional dentition. Pediatr Dent. 2004;26:417-420.

7. Lorton L. A method to facilitate impressions of orthodontically banded teeth. J Prosthet Dent. 1982;48:356.

8. Sukotjo C, Bocage V. Simplified fabrication of surgical template for orthodontic-implant treatment. J Prosthodont. 2006;15:59-61.
9. Alani A, Corson M. Soft tissue manipulation for single implant restorations. Br Dent J. 2011;211:411-416.

10. Tarlow JL. Procedure for obtaining proper contour of an implantsupported crown, a clinical report. J Prosthet Dent. 2002;87:416-418.

11. Macintosh DC, Sutherland M. Method for developing an optimal emergence profile using heat-polymerized provisional restorations for single-tooth implant-supported restorations. J Prosthet Dent. 2004;91:289-292.

12. Reikie DF. Restoring gingival harmony around single tooth implants. J Prosthet Dent. 1995;74:47-50.

13. Spyropoulou PE, Razzoog M, Sierraalta M. Restoring implants in the esthetic zone after sculpting and capturing the periimplant tissues in rest position, a clinical report. J Prosthet Dent. 2009;102:345-347.

14. Becker W, Doerr J, Becker BE. A novel method for creating an optimal emergence profile adjacent to dental implants. J Esthet Restor Dent. 2012;24:395-400.

15. Ntounis A, Petropoulou A. A technique for managing and accurate registration of periimplant soft tissues. J Prosthet Dent. 2010;104:276-279.

16. Al-Harbi SA, Edgin WA. Preservation of soft tissue contours with immediate screw-retained provisional implant crown. J Prosthet Dent. 2007;98:329-332.

17. Azer SS. A simplified technique for creating a customized gingival emergence profile for implant-supported crowns. J Prosthodont. 2010;19:497-501.

18. Bednarz W. The thickness of periodontal soft tissue ultrasonic examination - current possibilities and perspectives. Dent Med Probl. 2011;48:303-310.

19. Matys J, Dominiak M. Assessment of pain during uncovering implants with Er:YAG laser or scalpel for second stage surgery. Adv Clin Exp Med. 2016, doi:10.17219/acem/62456.

20. Hsu YT, Shieh $\mathrm{CH}$, Wang HL. Using soft tissue graft to prevent midfacial mucosal recession following immediate implant placement. J Int Acad Periodontol. 2012;14:76-82.

21. Wee AG. Comparison of impression materials for direct multiimplant impressions. J Prosthet Dent. 2000;83:323-331.

22. Peutzfeldt A, Asmussen E. Accuracy of alginate and elastomeric impression materials. Scand J Dent Res. 1989;97:375-379.

23. Walsh LJ. Erbium dental lasers and bone modification. Aust Dent Pract. 2008;9:106-108.

24. Happe A, Körner G, Nolte A. The keyhole access expansion technique for flapless implant stage-two surgery, technical note. Int J Periodontics Restorative Dent. 2010;30:97-101.

25. Al-Khayatt AS, Eliyas S. Soft tissue handling during implant placement. Evid Based Dent. 2008;9:77.

26. Matys J, Botzenhart U, Gedrange T, Dominiak M. Thermodynamic effects after diode and Er:YAG laser irradiation of grade IV and $V$ titanium implants placed in bone - an ex vivo study. Preliminary report. Biomed Engineering/Biomed Technik. 2016, doi: 10.1515/bmt2015-0135. 